\title{
Alternative Healthy Eating Index 2010, Dietary Inflammatory Index and risk of mortality: results from the Whitehall II cohort study and meta-analysis of previous Dietary Inflammatory Index and mortality studies;
}

\author{
Nitin Shivappa ${ }^{1,2,3 *}$, James R. Hebert ${ }^{1,2,3}$, Mika Kivimaki ${ }^{4}$ and Tasnime Akbaraly ${ }^{4,5}$ \\ ${ }^{1}$ Cancer Prevention and Control Program, University of South Carolina, Columbia, SC 29208, USA \\ ${ }^{2}$ Department of Epidemiology and Biostatistics, Arnold School of Public Health, University of South Carolina, \\ Columbia, SC 29208, USA \\ ${ }^{3}$ Connecting Health Innovations LLC, Columbia, SC 29201, USA \\ ${ }^{4}$ Department of Epidemiology and Public Health, University College London, London, UK \\ ${ }^{5}$ MMDN (Molecular Mechanisms of Neurodegenerative Diseases), INSERM (Institut National de la Santé et de la Recherche \\ Médicale) U1198, EPHE (Ecole Pratique des Hautes Etudes), University Montpellier, Montpellier, F-34095 France
}

(Submitted 25 October 2016 - Final revision received 20 April 2017 - Accepted 16 June 2017)

\section{Abstract}

We aimed to examine the association between the Alternative Healthy Eating Index updated in 2010 (AHEI-2010), the Dietary Inflammatory Index $\left(\mathrm{DII}^{\mathrm{TM}}\right)$ and risk of mortality in the Whitehall II study. We also conducted a meta-analysis on the DII-based results from previous studies to summarise the overall evidence. Data on dietary behaviour assessed by self-administered repeated FFQ and on mortality status were available for 7627 participants from the Whitehall II cohort. Cox proportional hazards regression models were performed to assess the association between cumulative average of AHEI-2010 and DII scores and mortality risk. During 22 years of follow-up, 1001 participants died (450 from cancer, 264 from CVD). Both AHEI-2010 (mean = $48.7(\mathrm{sD} 10 \cdot 0)$ ) and DII (mean = 0.37 (sD 1.41)) were associated with all-cause mortality. The fully adjusted hazard ratio (HR) per SD, were 0.82; $95 \%$ CI 0.76, 0.88 for AHEI-2010 and 1.18; $95 \%$ CI 1.08 , 1.29 for DII. Significant associations were also observed with cardiovascular and cancer mortality risk. For DII, a meta-analysis (using fixed effects) from this and four previous studies showed a positive association of DII score with all-cause (HR=1.04; 95\% CI 1.03, 1.05, 28891deaths), cardiovascular ( $\mathrm{HR}=1.05 ; 95 \%$ CI 1.03, 1.07, 10424 deaths) and cancer mortality (HR $=1.05 ; 95 \%$ CI 1.03, 1.07, $n$ 8269). The present study confirms the validity to assess overall diet through AHEI-2010 and DII in the Whitehall II cohort and highlights the importance of considering diet indices related to inflammation when evaluating all-cause, cardiovascular and cancer mortality risk.

Key words: Dietary indices: Mortality risk: Whitehall II cohort study: Meta-analyses

Various studies have been conducted exploring diet and dietary components in relation to, both from all-cause and cause-specific mortality ${ }^{(1)}$. There has recently been a shift in the focus from individual nutrient and food studies to dietary pattern studies because dietary components are consumed in combination and are correlated with one another ${ }^{(2)}$. With the dietary pattern approach overall quality of takes into account the complexity of the diet and the potentially synergistic or antagonistic effects of individual dietary components ${ }^{(3)}$.

Chronic inflammation is known to be associated with a variety of chronic health conditions including arthritis, diverticulitis, CVD, diabetes $^{(4-6)}$, and common epithelial cancers, with colorectal cancer $(\mathrm{CRC})^{(7-9)}$ being the most extensively studied.
Dietary factors can contribute to an individual's underlying state of chronic inflammation ${ }^{(10,11)}$ and there is growing evidence that specific dietary components influence inflammation ${ }^{(12-14)}$, potentially influencing risk of all-cause, cancer and cardiovascular mortality ${ }^{(15-18)}$. We previously showed in the Whitehall II cohort that a high score in Alternative Healthy Eating Index (AHEI) score was associated both with inflammatory markers and mortality risk.

The Dietary Inflammatory Index (DII) was developed to characterize an individual's diet on a continuum from maximally anti- to pro-inflammatory ${ }^{(19)}$. Thus far, the DII has been found to be associated with C-reactive protein $(\mathrm{CRP})^{(20,21)}$, IL-6 ${ }^{(22-24)}$, and TNF- $\alpha^{(23)}$. Until now, the DII has been applied to

Abbreviations: AHEI-2010, Alternative Healthy Eating Index 2010; DII, Dietary Inflammatory Index; HR, hazard ratios.

* Corresponding author: Dr N. Shivappa, fax +1 803576 5624, email shivappa@mailbox.sc.edu

$\ddagger$ The original version of this article was published with the incorrect title. A notice detailing this has been published and the error rectified in the online and print PDF and HTML copies. 
mortality outcomes only in four cohort studies and no overall evaluation of this evidence exists. As the creation of the AHEI in 2002 which was based on foods and nutrients predictive of chronic disease risk, substantial evidence has emerged to support a role of additional dietary factors in the development of chronic disease and a new measure of diet quality that incorporates current scientific evidence on diet and health has been proposed: the AHEI- $2010^{(25)}$. In this analysis, we assessed the association between the DII, the AHEI-2010 and all-cause, cardiovascular, and cancer mortality risk in a population-based prospective cohort of British men and women participating in the Whitehall II cohort. A secondary objective was to summarise the overall evidence of the association between DII and mortality from the Whitehall II study and all previous studies using meta-analysis.

\section{Methods \\ Study population}

Participants of the Whitehall II study were London-based office staff, aged 35-55 years, who worked in 20 civil service departments at study inception ${ }^{(26)}$. Baseline screening (phase 1: 1985-1988, $n$ 10308) consisted of a clinical examination and a self-administered questionnaire. Subsequent phases of data collection alternated between a clinical examination along with a questionnaire survey (phase 3: 1991/1993, $n$ 8815; phase 5: 1997/1999, $n$ 7263; phase 7: 2002/2004, $n$ 6943; phase 9: 2007/ 2009) and a postal questionnaire alone (phases 2, 4, 8 and 10). After the study was described to each participant, written informed consent was obtained. The University College London Ethics Committee approved the study. Phase 3 (1991-1993) was considered the baseline for the purpose of this study, because it was the first assessment of the AHEI-2010 and DII. Analyses were carried out on the 7627 participants alive at phase 3 with information on vital status and with complete data on dietary indices and covariates at phase 3 .

\section{Dietary assessment}

Dietary intake at phase 3 was assessed with the use of a semiquantitative FFQ with 127 food items, as described previously $^{(27,28)}$. The validity and the reliability of the FFQ in terms of nutrient and food consumption have been documented in detail both in our cohort and in another independent UK cohort ${ }^{(28,29)}$. The selected frequency category for each food item was converted to a daily intake. Nutrient intakes were computed by multiplication of the consumption frequency for each food by its nutrient content (for specified portions), and then the nutrient contributions from all foods were summed. Frequency of consumption for multivitamin supplements was also collected. Nutrient values were calculated with the use of a computerised system developed for the Whitehall II dietary data.

Alternative Healthy Eating Index 2010. Scoring criteria for AHEI-2010 are described in detail elsewhere ${ }^{(25)}$. The AHEI-2010 is based on eleven components: six components for which the highest intakes were supposed to be ideal (vegetables, fruit, whole grains, nuts and legumes, long chain $n$ - 3 fats (DHA and EPA), and PUFA), one component for which moderate intake was supposed to be ideal (alcohol), and four components for which avoidance or lowest intake were supposed to be ideal (sugar sweetened drinks and fruit juice, red and processed meat, trans-fat, and $\mathrm{Na}$ ). Each component is given a minimal score of 0 and a maximal score of 10, with intermediate values scored proportionally, and has the potential to contribute 0-10 points to the total score. All the component scores are summed to obtain a total AHEI-2010 score, which ranges from 0 to 110 , with a higher score representing a healthier diet (see online Supplementary Material for the distribution of the baseline score).

Dietary inflammatory index. The DII is based on literature published through 2010 linking diet to inflammation. Developing the DII involved reviewing and scoring nearly 2000 scientific articles on diet and six inflammatory markers (i.e. CRP, IL- $1 \beta$, IL- 4 , IL-6, IL-10 and TNF- $\alpha$ ) based on cell culture and laboratory animal experiments, and cross-sectional, longitudinal and intervention trials in humans. Individual intakes of food parameters on which the DII is based have then been compared with a world standard database of dietary intake based on datasets from eleven different regions worldwide. A complete description of the DII is available elsewhere. In brief, to calculate DII scores for participants in this study, the dietary data at phase 3 were first linked to the world database that provided a robust estimate of a mean and standard deviation for each parameter ${ }^{(19)}$. These then become the multipliers to express an individual's exposure relative to the 'standard global mean' as a $z$ score. This is achieved by subtracting the 'standard global mean' from the amount reported and dividing this value by the standard deviation. To minimise the effect of 'right skewing', we converted this value to a centred percentile score. The centred percentile score for each food parameter for each individual was then multiplied by the respective food parameter-specific inflammatory effect score, which was derived from the literature review, in order to obtain a food parameter-specific DII score for an individual. All of the food parameter-specific DII scores were then summed to create the overall DII score for each participant in the study ${ }^{(19)}$. A description of validation of the DII, including comparing hs-CRP values to DII derived from both dietary recalls and a structured questionnaire similar to an FFQ, is available elsewhere ${ }^{(19)}$. More negative values represent more anti-inflammatory diets. The DII score when calculated from all forty-five food parameters could range from a global minimum of -8.87 (maximally anti-inflammatory) to a global maximum +7.98 (maximally pro-inflammatory), though the typical observed range in most studies where DII is calculated from an average of twenty-seven food parameters is from about $-5 \cdot 5$ to $+5 \cdot 5^{(24,30,31)}$. Details regarding the construct validation of the DII have been detailed elsewhere ${ }^{(19)}$. In the present study, a total of twentyseven of forty-five food parameters were available from the FFQ and were used to calculate the DII. These include energy, carbohydrate, protein, total fat, alcohol, fibre, cholesterol, SFA, MUFA, PUFA, n-3, n-6, trans-fat, niacin, thiamine, riboflavin, vitamin $\mathrm{B}_{12}$, $\mathrm{B}_{6}, \mathrm{Fe}, \mathrm{Mg}, \mathrm{Zn}$, Se, vitamin A, vitamin C, vitamin D, vitamin E, folic acid. Steps involved in the DII calculation are described in the 
online Supplementary Fig. A. DII scores were calculated from nutrients derived only from dietary items.

We compute the AHEI-2010 and the DII scores from each FFQ administrated in phase 3 (1991-1993), phase 5 (1997-1999) and phase 7 (2002-2004). To reduce measurement errors and to represent long-term dietary intake, we calculated the cumulative average of AHEI-2010 and DII.

\section{Mortality assessment}

The Whitehall II study is linked to the National Health Services death and electronic patient records with the use of the National Health Services identification number assigned to all British citizens. A total of 10297 participants (99.9\%) were successfully traced and have been followed through these registries. Mortality data, which included the date and cause of death, were available through the National Health Services Central Registry until 28 February 2015. Death certificates were coded with the use of the 9th or 10th revision of the International Classification of Diseases (ICD) (http://www.who.int/classifications/ icd/en/). We analysed all-cause mortality and mortality from specific causes, such as CVD (ICD-9 codes 390.0-458.9 and ICD-10 codes I00-I99) and cancer (ICD-9 140.0-209.9 and ICD-10 C00-C97). Non-cancer/non-CVD mortality includes all remaining deaths that are classified neither as cancer nor CVD, and included deaths from diseases of the respiratory system (most common other cause of death), digestive system, or nervous system; injuries; poisoning; and external causes.

\section{Covariates}

Socio-demographic variables consisted of age, sex, ethnicity (White/South Asian/Black), marital status (married or cohabiting $v$. living alone) and occupational position with the use of current (or last, for retired participants) British civil service employment grade, defined on the basis of salary and grouped into three categories: high (senior administrators)/ intermediate (executives, professionals and technical staff)/low (clerical and office support staff) grades.

Health behaviours included in the analysis were smoking (current/former/non-smoker), total energy intake estimated from the FFQ (in $\mathrm{kJ} / \mathrm{d}(\mathrm{kcal} / \mathrm{d})$ ), alcohol intake patterns (none: 0 glass/d, moderate: <2 (3) glasses/d for women (men), and heavy consumption: $\geq 2$ (3) glasses/d for women (men)) and physical activity assessed via questionnaire data and categorised into three groups (high, intermediate, low) according to frequency of participation in 'vigorous' (e.g. running, hard swimming, playing squash), 'moderately energetic' (e.g. dancing, cycling, leisurely swimming) and 'mildly energetic' physical activity ${ }^{(32)}$. Health status was ascertained with the use of a number of measures: prevalence of CVD on the basis of clinically verified events, which included non-fatal myocardial infarction, definite angina, selfreported stroke or transient ischaemic attack; hypertension (systolic or diastolic blood pressure $\geq 140$ or $\geq 90 \mathrm{mmHg}$, respectively, or use of hypertensive drugs); concentration of HDLcholesterol (mmol/l), use of lipid-lowering drugs; type 2 diabetes (diagnosed with the use of the WHO definition); BMI $\left(\mathrm{kg} / \mathrm{m}^{2}\right.$ ) and self-reported longstanding illness (participants responded to a question asking if they had a longstanding illness: yes/no).
Covariates were obtained from the baseline questionnaire (phase 3) and updated every 5 years (at phase 5 and phase 7). All variables (other than sex and ethnicity) included timevarying covariates.

\section{Statistical analysis}

Characteristics of participants as a function of mortality status were first described and tested using $\chi$ tests for categorical variables and Student $t$ test for continuous variables. Next, comparison of characteristics associated with DII and AHEI-2010 tertiles were performed using chi-square tests for categorical variables and ANOVA for continuous variables. Associations between AHEI-2010 and DII tertiles were assessed using chi-square tests.

The main analyses consisted of exploring the association between the risk of mortality and the cumulative average of AHEI-2010 and DII scores in the Whitehall II cohort. Stratified proportional Cox hazard models analyses were used to calculate hazard ratios (HR) and 95\% CI for death. In these analyses the AHEI-2010 and DII were first considered as continuous variables by using $z$ scores. Then AHEI-2010 and DII were categorised into tertiles, with the lowest tertile serving as the reference group for both indices. We calculated a test for trend across the tertiles of the AHEI-2010 and DII score by treating the categories as an ordinal variable in a proportional hazards model. We used three multivariable models, In model 1 we adjusted age, sex and ethnicity; in model 2 we additionally adjusted for occupational grade, living alone, smoking habits, alcohol consumption (only for DII), physical activity; and model 3 was further adjusted for health status factors including BMI, antecedent of CVD, use of lipid-lowering drugs, HDL-cholesterol, hypertension, type 2 diabetes and longstanding illness. These time-varying covariates were chosen a priori as they previously had been shown to be strong risk factors for mortality in this cohort. To minimise the effect of missingness, we replaced missing data on these covariates with the last valid values. These analyses of the association between DII, AHEI-2010 and overall mortality were repeated for causespecific mortality including cardiovascular and cancer mortality. Stratified analyses also were carried out by tertiles of energy intake. Analyses were performed using SAS ${ }^{\circledR}$ statistical software, version 9.4 .

A second analysis focused on meta-analysis of DII results from Whitehall II plus all four previous studies. To date, there have been four other studies ${ }^{(33-36)}$ published on the DII and mortality. We synthesised this evidence by pooling effect estimates from those studies and the current study. As the number of studies was modest ${ }^{(37)}$ fixed-effects meta-analysis was used. For comparison, we repeated the analysis using an alternative approach, random-effects meta-analysis. We used continuous DII score as the exposure because results for that variable were available from all five studies and therefore could be compared directly. Mortality analyses were restricted to deaths from all-causes, cancer and CVD. Heterogeneity in study-specific estimates was evaluated using $\mathrm{I}^{2}$ statistics. All meta-analyses were performed using Stata ${ }^{\circledR}$, version MP.13.1 with the 'metan' command (online Supplementary Table F). 
Table 1. Description of Cumulative average of Alternative Healthy Eating Index 2010 (AHEI-2010) and Dietary Inflammatory Index (DII) score categorised in tertile according to participants characteristics(Mean values and standard deviations; medians and ranges; numbers and percentages)

\begin{tabular}{|c|c|c|c|c|c|c|c|c|c|c|c|c|c|c|}
\hline & \multicolumn{7}{|c|}{ Tertiles of AHEI-2010 } & \multicolumn{7}{|c|}{ Tertiles of DII } \\
\hline & \multicolumn{2}{|c|}{$\begin{array}{c}\text { Tertile } 1 \\
\text { (unhealthiest) }\end{array}$} & \multicolumn{2}{|c|}{ Tertile 2} & \multicolumn{2}{|c|}{$\begin{array}{c}\text { Tertile } 3 \\
\text { (healthiest) }\end{array}$} & \multirow[b]{2}{*}{$P$} & \multicolumn{2}{|c|}{$\begin{array}{c}\text { Tertile } 1 \\
\text { (most anti- } \\
\text { inflammatory) }\end{array}$} & \multicolumn{2}{|c|}{ Tertile 2} & \multicolumn{2}{|c|}{$\begin{array}{c}\text { Tertile } 3 \\
\text { (most pro-inflammatory) }\end{array}$} & \multirow[b]{2}{*}{$P$} \\
\hline & $n$ & $\%$ & $n$ & $\%$ & $n$ & $\%$ & & $n$ & $\%$ & $n$ & $\%$ & $n$ & $\%$ & \\
\hline$n$ & \multicolumn{2}{|c|}{2534} & \multicolumn{2}{|c|}{2516} & \multicolumn{2}{|c|}{2577} & & \multicolumn{2}{|c|}{2542} & \multicolumn{2}{|c|}{2543} & & & \\
\hline Mean & & & 54 & & & & & & 08 & 0 . & & & & \\
\hline SD & & & 2 & & 5 & & & & & 0 & & & & \\
\hline Median & & & 55 & & & & & & 98 & 0 & & & & \\
\hline Range & $23 \cdot 0$ & $50 \cdot 7$ & $51 \cdot 0$ & $-58 \cdot 7$ & $59 \cdot 0$ & $-89 \cdot 0$ & & -3.0 & -0.39 & -0.35 & -0.75 & & & \\
\hline Characteristics of participants & & & & & & & & & & & & & & \\
\hline $\begin{array}{l}\text { Sex (men) } \\
\text { Age (years) }\end{array}$ & 1807 & $71 \cdot 3$ & 1748 & 69.5 & 1753 & $68 \cdot 0$ & $\begin{array}{r}0.04 \\
<0.001\end{array}$ & 1760 & $69 \cdot 2$ & 1814 & $71 \cdot 3$ & 1734 & $68 \cdot 2$ & $\begin{array}{c}0.04 \\
<0.001\end{array}$ \\
\hline Mean & & & 50 & & & & & & & 50 & & & & \\
\hline SD & & & 5 & & 6 & & & & & 6 & & & & \\
\hline Ethnicity (white) & 2394 & 94.5 & 2310 & $91 \cdot 8$ & 2264 & $87 \cdot 8$ & $<0.001$ & 2364 & 93.0 & 2343 & $92 \cdot 1$ & 2261 & 88.9 & $<0.001$ \\
\hline Occupational grade ${ }^{*}$ (low) & 500 & $19 \cdot 7$ & 392 & $15 \cdot 6$ & 341 & $13 \cdot 2$ & $<0.001$ & 364 & $14 \cdot 3$ & 354 & $13 \cdot 9$ & 515 & $20 \cdot 2$ & $<0.001$ \\
\hline Marital status (married/cohabited) & 1857 & $73 \cdot 3$ & 1978 & $78 \cdot 6$ & 2021 & $78 \cdot 4$ & $<0.001$ & 1979 & $77 \cdot 8$ & 2003 & $78 \cdot 8$ & 1874 & $73 \cdot 7$ & $<0.001$ \\
\hline Smoking status (non-smokers) & 1141 & $45 \cdot 0$ & 1267 & $50 \cdot 4$ & 1436 & 55.7 & $<0.001$ & 1340 & $52 \cdot 7$ & 1322 & $52 \cdot 0$ & 1182 & $46 \cdot 5$ & $<0.001$ \\
\hline Alcohol consumptiont (heavy) & 671 & $26 \cdot 5$ & 380 & $15 \cdot 1$ & 267 & $10 \cdot 4$ & $<0.001$ & 475 & 18.7 & 415 & $16 \cdot 3$ & 428 & $16 \cdot 8$ & 0.001 \\
\hline Physical activity $\ddagger$ (low) & 588 & $23 \cdot 2$ & 498 & $19 \cdot 8$ & 452 & $17 \cdot 5$ & $<0.001$ & 399 & $15 \cdot 7$ & 478 & $18 \cdot 8$ & 661 & $26 \cdot 0$ & $<0.001$ \\
\hline BMl $\left(\mathrm{kg} / \mathrm{m}^{2}\right)$ & & & & & & & $<0.001$ & & & & & & & 0.01 \\
\hline Mean & & & 25 & & & & & & & 25 & & & & \\
\hline SD & & & 3 & & 3 & & & & & 3 & & & & \\
\hline Hypertension & 528 & $20 \cdot 8$ & 506 & $20 \cdot 1$ & 425 & $16 \cdot 5$ & $<0.001$ & 510 & $20 \cdot 1$ & 460 & $18 \cdot 1$ & 489 & $19 \cdot 2$ & 0.20 \\
\hline Type 2 diabetes & 93 & 3.7 & 70 & $2 \cdot 8$ & 74 & 2.9 & 0.13 & 88 & 3.5 & 71 & $2 \cdot 8$ & 78 & $3 \cdot 1$ & 0.38 \\
\hline Antecedent of CVD & 72 & $2 \cdot 8$ & 78 & $3 \cdot 1$ & 87 & $3 \cdot 4$ & 0.54 & 96 & 3.8 & 61 & $2 \cdot 4$ & 79 & $3 \cdot 1$ & 0.02 \\
\hline HDL-cholesterol (mmol/l) & & & & & & & $<0.001$ & & & & & & & $0 \cdot 10$ \\
\hline Mean & & & 1 & & & & & & & 1 & & & & \\
\hline SD & & & 0 & & & & & & & 0 & & & & \\
\hline Use of lipid-lowering drugs & 11 & 0.4 & 21 & 0.8 & 24 & 0.9 & 0.09 & 26 & 1.0 & 15 & 0.6 & 15 & 0.6 & 0.11 \\
\hline Longstanding illness & 859 & 33.9 & 854 & 33.9 & 861 & 33.4 & 0.90 & 918 & $36 \cdot 1$ & 844 & $33 \cdot 2$ & 812 & 31.9 & 0.005 \\
\hline Total energy intake $(\mathrm{kJ} / \mathrm{d})$ & & & & & & & 0.13 & & & & & & & $<0.001$ \\
\hline Mean & & & 88 & & & & & 10 & 481 & 89 & & & & \\
\hline SD & & & 24 & & 23 & & & & 544 & 18 & & & & \\
\hline Total energy intake (kcal/d) & & & & & & & 0.13 & & & & & & & $<0.001$ \\
\hline Mean & & & 21 & & & & & & 505 & 21 & & & & \\
\hline SD & & & & 90 & & 53 & & & 08 & & 48 & & & \\
\hline Carbohydrate (g/d) & & & & & & & $<0.01$ & & & & & & & $<0.001$ \\
\hline Mean & & & & 61 & & 74 & & & 315 & & & & & \\
\hline SD & & 31 & & 78 & & 75 & & & 78 & & 59 & & & \\
\hline Fibre $(g / d)$ & & & & & & & $<0.001$ & & & & & & & $<0.001$ \\
\hline Mean & & 2 & & 25 & & 30 & & & 34 & & 25 & & & \\
\hline SD & & 7 & & 8 & & 9 & & & 8 & & 5 & & & \\
\hline Protein $(\mathrm{g} / \mathrm{d})$ & & & & & & & 0.01 & & & & & & & $<0.001$ \\
\hline Mean & & 0 & & 91 & & 92 & & & 108 & & 90 & & & \\
\hline SD & & 6 & & 25 & & 25 & & & 25 & & 19 & & & \\
\hline Total fat $(\mathrm{g} / \mathrm{d})$ & & & & & & & $<0.001$ & & & & & & & $<0.001$ \\
\hline Mean & & 30 & & 77 & & 76 & & & 88 & & 77 & & & \\
\hline SD & & 30 & & 27 & & 25 & & & 31 & & 24 & & & \\
\hline MUFA (g/d) & & & & & & & $<0.001$ & & & & & & & $<0.001$ \\
\hline Mean & & 4 & & 23 & & 23 & & & 26 & & 23 & & & \\
\hline SD & & 9 & & 8 & & 8 & & & 10 & & 7 & & & \\
\hline PUFA (g/d) & & & & & & & $<0.001$ & & & & & & & $<0.001$ \\
\hline Mean & & 4 & & 15 & & 17 & & & 19 & & 15 & & & \\
\hline SD & & 6 & & 6 & & 7 & & & 7 & & 6 & & & \\
\hline
\end{tabular}

* Occupational position with the use of current (or last for retired participants) British civil service employment grade, was defined on the basis of salary and grouped into three categories: high (senior administrators)/intermediate (executives, professionals and technical staff)/low (clerical and office support staff) grades.

† Alcohol intake categories were defined as none: 0 glass/d; moderate: <2 (3) glasses/d for women (men); and heavy consumption: $\geq 2$ (3) glasses/d for women (men).

‡ Physical activity was categorised into three groups (high, intermediate, low) according to frequency of participation in 'vigorous' (e.g. running, hard swimming, playing squash), 'moderately energetic' (e.g. dancing, cycling, leisurely swimming) and 'mildly energetic' physical activity.

\section{Results}

Analyses from the Whitehall II study were carried out on the 7627 participants alive at phase 3 with information on vital status and with data on dietary indices and covariates as described in the flow chart mapping the selection of participants (online Supplementary
Fig. B). Characteristics of these participants as a function of mortality status are detailed in the online Supplementary Table A. Cumulative distribution of AHEI-2010 and DII score are presented in Table 1. DII had a mean value of 0.37 (SD 1.41), with a range from -3.28 (most anti-inflammatory score) to +4.54 (most pro-inflammatory score). AHEI had a mean value of 48.7 (SD 10.0), with a range from 
$15 \cdot 5$ (least healthy diet) to $85 \cdot 5$ (healthiest diet). Participants in the highest tertile of AHEI-2010 (reflecting a healthier diet) compared with those in the lowest tertile (reflecting an unhealthier diet) were less likely to be men, white with a low socioeconomic position and more likely to be older, to be married, and to have healthy behaviours (smoking habits, alcohol consumption and physical activity). Their average mean of total energy intake was also higher. Regarding health factors, the group of participants in the highest tertile of AHEI-2010 were less likely to have hypertension, they showed higher means of HDL-cholesterol and lower means of BMI. Regarding nutrients, participants in the highest tertile of AHEI-2010 had higher carbohydrate, fibre, protein and PUFA and lower total fat and MUFA consumption. Similar pattern of socio-demographic, health behaviour, health status factors and nutrients associated with DII tertiles were observed.

The correlation coefficient between AHEI-2010 and DII was -0.41 . In Table 2 we show that $54.4 \%$ of participants in tertile 1 of DII; that is, with the most anti-inflammatory diets, are in tertile 3 of AHEI-10 (corresponding to the healthiest diet) and

Table 2. Relationship between Alternative Healthy Eating Index 2010 (AHEI-2010) and Dietary Inflammatory Index (DII)

(Numbers and percentages)

\begin{tabular}{|c|c|c|c|c|c|c|}
\hline \multirow[b]{3}{*}{ AHEI-2010 tertiles } & \multicolumn{6}{|c|}{ DIl tertiles } \\
\hline & \multicolumn{2}{|c|}{$\begin{array}{c}\text { Tertile } 3 \\
\text { (most pro- } \\
\text { inflammatory) }\end{array}$} & \multicolumn{2}{|c|}{ Tertile 2} & \multicolumn{2}{|c|}{$\begin{array}{c}\text { Tertile 1 } \\
\text { (most anti- } \\
\text { inflammatory) }\end{array}$} \\
\hline & $n$ & $\%$ & $n$ & $\%$ & $n$ & $\%$ \\
\hline Tertile 1 (unhealthy diet) & 1319 & $51 \cdot 9$ & 860 & 33.8 & 461 & $18 \cdot 1$ \\
\hline Tertile 2 & 809 & $31 \cdot 8$ & 825 & $32 \cdot 4$ & 698 & 27.5 \\
\hline Tertile 3 (healthiest diet) & 414 & $16 \cdot 2$ & 858 & 33.7 & 1383 & $54 \cdot 4$ \\
\hline
\end{tabular}

$51.9 \%$ of participants in tertile 3 of DII, that is, with the most pro-inflammatory diets, are in tertile 1 of AHEI (corresponding to the unhealthiest diet). However, there is some discordance, $18.1 \%$ of participants in the most anti-inflammatory group (tertile 1) of DII are in the unhealthiest diet group for AHEI-2010

In total, 1001 total deaths were identified during the 22 years of follow-up; 450 cancer deaths, 254 cardiovascular deaths. As illustrated in Fig. 1 and 2, both AHEI-2010 and DII were associated with all-cause mortality. Whatever the model, for each SD increment of AHEI-2010 ( 9.8 points) a $20 \%$ reduced risk of mortality was observed, and for DII, one increment of $1 \mathrm{SD}$ ( 1.3 points) was associated with an increased by $20 \%$ of mortality HR. Results of the analyses in which AHEI-2010 and DII scores were categorised in tertiles are concordant with these findings (results are presented in online Supplementary Table C). In sex-, age- and ethnicity-adjusted model, participants in the 3rd and 2nd tertiles of AHEI-2010 showed, respectively, 30 and $40 \%$ reduced risk of all-cause mortality risk over the 22 years of follow-up. Further adjustment for health behaviours (occupational grade, living alone, smoking habits, physical activity and total energy intake) in model 2 and health status factors (BMI, antecedent of CVD, use of lipid-lowering drugs, HDL-cholesterol, hypertension, type 2 diabetes and longstanding illness) in model 3) did not substantially attenuate the association. The online Supplementary Table C shows that cumulative average of AHEI score tertiles remained significantly associated with mortality risk after full adjustment (model 3) $\left(\mathrm{HR}_{\text {Tertile }} 3 v\right.$. Tertile $1=0.73 ; 95 \% \mathrm{CI} 0 \cdot 69,0 \cdot 87 ; \mathrm{HR}_{\text {Tertile } 2 v \text {. Tertile } 1}=$ $0.79 ; 95 \%$ CI 0.66, 0.93; $\left.P_{\text {trend }}<0.001\right)$. Regarding DII, participants in tertile 3 (most pro-inflammatory group) had $47 \%$ higher risk of all-cause mortality compared with participants in tertile 1 (most anti-inflammatory group) $\left(\mathrm{HR}_{\text {Tertile }} 3 v\right.$. Tertile $1=1 \cdot 47 ; 95 \%$ CI $1 \cdot 19$, $\left.1 \cdot 82 ; P_{\text {trend }}<0 \cdot 001\right)$. Regarding the important differences in total

All-cause mortality \begin{tabular}{l|l}
$\mathrm{H}=0.77(0.71,0.83), P<0.001$ \\
$\mathrm{HR}=0.82(0.76,0.88), P<0.001$ \\
$\mathrm{HR}=0.82(0.76,0.88), P<0.001$
\end{tabular}

Fig. 1. Associations between cumulative average of Alternative Healthy Eating Index 2010 (AHEI-2010) and mortality risk over 22 years of follow-up for the 7627 Whitehall II participants. Values are hazard ratios (HR) and $95 \% \mathrm{Cl}$. Cox proportional hazards models estimated the HR of mortality for $1 \mathrm{sD}$ of AHEI-2010. In these multivariate models $(M)$ the covariates were time-varying variables. Model 1: model adjusted for age, sex and ethnicity. Model 2: model 1 further adjusted for occupational grade, marital status, smoking habits, physical activity and total energy intake. Model 3: model 2 further adjusted for BMI, antecedent of CVD, use of lipid-lowering drugs, HDL-cholesterol, hypertension, type 2 diabetes and longstanding illness. 


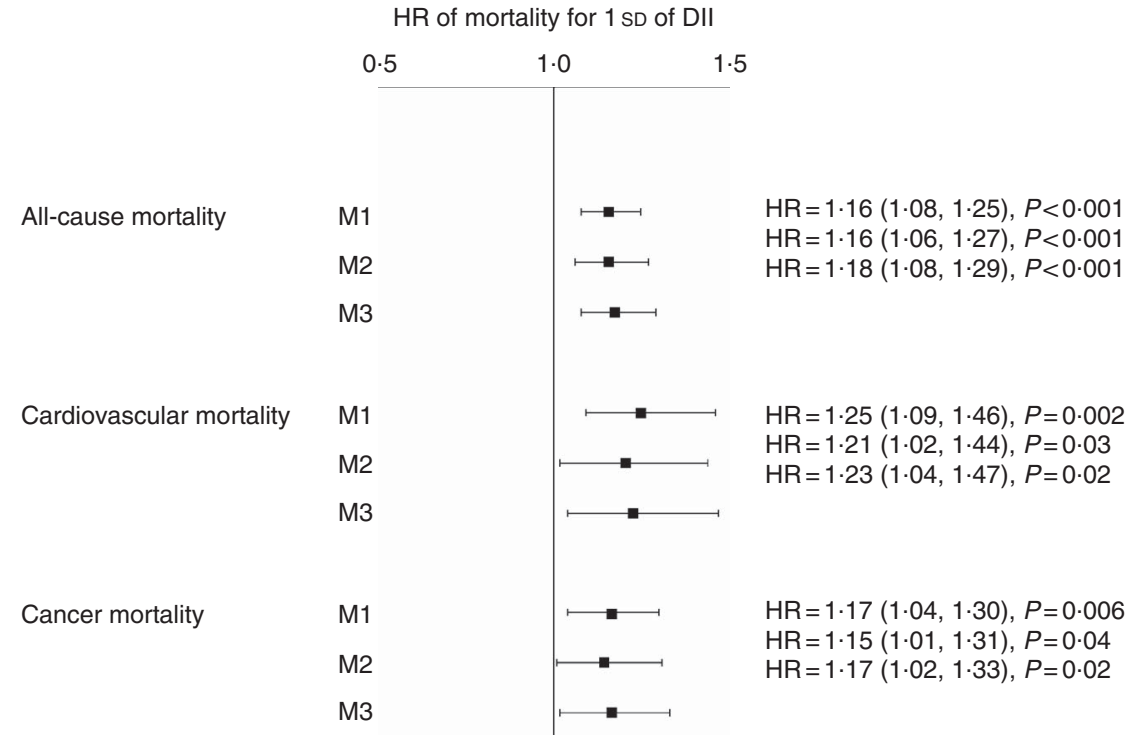

Fig. 2. Associations between cumulative average of Dietary Inflammatory Index (DII) and mortality risk over 22 years of follow-up for the 7627 Whitehall II participants. Values are hazard ratios (HR) and $95 \% \mathrm{Cl}$. Cox proportional hazards models (M) estimated the HR of mortality for $1 \mathrm{sD}$ of DII. In these multivariate models the covariates were time-varying variables. Model 1: model adjusted for age, sex and ethnicity. Model 2: model 1 further adjusted for occupational grade, marital status, smoking habits, alcohol consumption physical activity and total energy intake. Model 3: model 2 further adjusted for BMI, antecedent of CVD, use of lipid-lowering drugs, HDL-cholesterol, hypertension, type 2 diabetes and longstanding illness.

energy intake, average means across DII tertiles, we carried out an additional analysis to describe the DII - all-cause mortality association across total energy intake tertiles. Results (online Supplementary Table B) showed that the DII was significantly associated with all-cause mortality only among participants in the lowest tertile of total energy intake $\left(\mathrm{HR}_{\text {Tertile }} 3 v\right.$. Tertile $1=1.72$; $95 \%$ CI $1.08,2 \cdot 72 ; P_{\text {trend }}=0.02$ ).

Over the 22 years of follow-up, 264 death caused by CVD occurred. Results of the association between cumulative average of AHEI-2010 and DII scores and risk of cardiovascular mortality are detailed in Fig. 1 and 2 and in the online Supplementary Table D. Higher AHEI-2010 score was consistently associated with lower risk of cardiovascular mortality whatever the level of adjustment considered (in full adjusted model, HR= 0.80; 95\% CI 0.69, 0.93). Similar results were observed when tertiles of AHEI-2010 and DII were considered (AHEI-2010, $\mathrm{HR}_{\text {Tertile } 3} v$. Tertile $1=0.68 ; 95 \%$ CI $\left.0.48,0.95 ; P_{\text {trend }}=0.03\right)$; and (DII, $\mathrm{HR}_{\text {Tertile } 3} v$. Tertile $1=1.46 ; 95 \%$ CI 1.00, 2.13; $P_{\text {trend }} 0.05$ ).

Regarding cancer mortality, 450 death occurred over the follow-up. Fig. 1 shows that AHEI-2010 was significantly associated with lower risk of cancer mortality $(\mathrm{HR}=0 \cdot 87 ; 95 \% \mathrm{CI}$ $0 \cdot 78,0.98)$. The online Supplementary Table E confirms that in sex-, age- and ethnicity-adjusted models, participants in higher tertiles of AHEI-2010 showed a lower risk of cancer mortality compared with those in the bottom tertile. However further adjustment for health behaviour and health status factors substantially attenuate the association. Participants with high DII score showed a significant higher risk of cancer mortality and this association remained statistically significant whatever way the DII was analysed and no matter the level of adjustment (Fig. 2 and online Supplementary Table E).

To our knowledge four other previous studies investigated the DII-mortality risk (all cause, and caused by CVD or by cancer). A full description of these studies is provided in Table 3. DII for the Iowa Women's Health Study in the USA was calculated from FFQ that was adapted from the 126-item instrument developed by Willett et al., in total there were twenty-seven food parameters that were used for DII calculation and this study had information on supplement use ${ }^{(35)}$. DII scores for the Swedish Mammography Cohort were calculated using a ninety-six-item FFQ from twenty-seven food parameters without supplements ${ }^{(36)}$. In the National Health and Nutrition Examination Survey III study in the USA, DII was calculated using $24 \mathrm{~h}$ recall without supplements from twenty-seven food parameters ${ }^{(34)}$. In the Supplementation en Vitamines et Mineraux Antioxydants (SUVIMAX) study conducted in France, DII was calculated using multiple $24 \mathrm{~h}$ records from thirty-seven food parameters ${ }^{(33)}$. We combine these results with those from the Whitehall II study. We then conducted a meta-analysis on data from the total of 91520 participants across the five studies. Fig. 3-5 show positive associations between DII score and allcause, cardiovascular and cancer mortality, respectively. The pooled HR from fixed and random effect models were 1.04 (95\% CI 1.03, 1.05) and 1.05 (95\% CI 1.03, 1.07) for all-cause mortality (28891 deaths), 1.05 (95\% CI 1.03, 1.07) and 1.05 (95\% CI 1.03, 1.08) for cardiovascular mortality (10 424 deaths); and 1.05 (95\% CI 1.03, 1.07) and 1.06 (95\% CI 1.02, 1.09) for cancer mortality (8269 deaths). Thus, no differences were observed in summary estimates between the two methods of meta-analysis.

\section{Discussion}

In this prospective cohort study of 7627 British men and women, adherence to healthy diet assessed by the AHEI-2010 was associated with lower risk of all-cause, cardiovascular 
Table 3. Characteristics of included studies

(Mean values and standard deviations)

\begin{tabular}{|c|c|c|c|c|c|c|c|c|c|c|}
\hline & $\begin{array}{l}\text { Sample } \\
\text { size }\end{array}$ & $\begin{array}{l}\text { Follow-up } \\
\text { (years) }\end{array}$ & $\begin{array}{l}\text { Dietary } \\
\text { assessment tool } \\
\text { used }\end{array}$ & $\begin{array}{l}\text { Number of food } \\
\text { parameters } \\
\text { used for DII } \\
\text { calculation }\end{array}$ & Mean & SD & $\begin{array}{l}\text { DIl included } \\
\text { information from } \\
\text { supplements }\end{array}$ & Assessment of mortality & $\begin{array}{c}\text { Total number of } \\
\text { deaths }\end{array}$ & Adjustment \\
\hline Whitehall II & 7622 & 22 & 127-item FFQ & 27 & 0.37 & 1.41 & No & $\begin{array}{l}\text { Deaths were identified by } \\
\text { linkage to the National } \\
\text { Health Services death and } \\
\text { electronic patient records } \\
\text { with the use of the National } \\
\text { Health Services } \\
\text { identification number } \\
\text { assigned to all British } \\
\text { citizens }\end{array}$ & 1001 & $\begin{array}{l}\text { Adjusted for age, sex, ethnicity, } \\
\text { occupational grade, living alone, } \\
\text { smoking habits, alcohol } \\
\text { consumption, physical activity, } \\
\text { total energy intake, BMI, } \\
\text { antecedent of CVD, use of } \\
\text { lipid-lowering drugs, HDL- } \\
\text { cholesterol, hypertension, type } 2 \\
\text { diabetes and longstanding } \\
\text { illness }\end{array}$ \\
\hline NHANES III & 12366 & 18 & 24-h recalls & 27 & 0.73 & $2 \cdot 20$ & No & $\begin{array}{l}\text { Death were identified through } \\
\text { linkage to National Death } \\
\text { Index records through } \\
31 \text { December 2006, by the } \\
\text { National Center for Health } \\
\text { Statistics }\end{array}$ & 2795 & $\begin{array}{l}\text { Adjustment was made for age, } \\
\text { BMI, smoking status, sex, race/ } \\
\text { ethnicity, diabetes status, } \\
\text { hypertension status, physical } \\
\text { activity, medical history of CVD, } \\
\text { and poverty index }\end{array}$ \\
\hline $\begin{array}{l}\text { Swedish } \\
\text { Mammography } \\
\text { Cohort }\end{array}$ & 33747 & 15 & 96-item FFQ & 27 & 0.64 & 1.45 & No & $\begin{array}{l}\text { Death were identified through } \\
\text { linkage to the Swedish } \\
\text { Cause of Death Registry at } \\
\text { National Board of Health } \\
\text { and Welfare }\end{array}$ & 7095 & $\begin{array}{l}\text { Adjusted for age, energy intake, } \\
\text { BMI, education, smoking status, } \\
\text { physical activity and alcohol } \\
\text { intake }\end{array}$ \\
\hline $\begin{array}{l}\text { lowa Women's } \\
\text { Health Study }\end{array}$ & 37525 & 24 & $\begin{array}{l}\text { Adapted from the } \\
126 \text {-item FFQ } \\
\text { developed by } \\
\text { Willett and group } \\
\text { at Harvard }\end{array}$ & 27 & -0.87 & 2.02 & Yes & $\begin{array}{l}\text { Deaths were identified through } \\
\text { the State Health Registry of } \\
\text { lowa or the National Death } \\
\text { Index for women who did not } \\
\text { respond to the last follow-up } \\
\text { questionnaire (2004) or who } \\
\text { emigrated from lowa }\end{array}$ & 17793 & $\begin{array}{l}\text { Adjusted for age, BMI, smoking } \\
\text { status, pack-years of smoking, } \\
\text { HRT use, education, prevalent } \\
\text { diabetes, prevalent } \\
\text { hypertension, prevalent heart } \\
\text { disease, prevalent cancer, total } \\
\text { energy intake }\end{array}$ \\
\hline SUVIMAX & 8089 & 13 & $\begin{array}{l}\text { 24-h dietary } \\
\text { records }\end{array}$ & 37 & $\begin{array}{c}0.6 \\
\text { (women), } \\
0.8 \text { (men) }\end{array}$ & $\begin{array}{c}1.7 \\
\text { (women), } \\
1.5 \text { (men) }\end{array}$ & No & $\begin{array}{l}\text { Death were identified from } \\
\text { relatives or physicians } \\
\text { during follow-up. At the end } \\
\text { of follow-up, vital status of all } \\
\text { subjects of the cohort and } \\
\text { causes of death were } \\
\text { verified with the national } \\
\text { death registry (CépiDC) }\end{array}$ & 207 & $\begin{array}{l}\text { Adjusted for age, sex, intervention } \\
\text { group of the initial SU.VI.MAX } \\
\text { trial, number of 24-h dietary } \\
\text { records, BMI, physical activity, } \\
\text { smoking status, educational } \\
\text { level, family history of cancer in } \\
\text { first-degree relatives, family } \\
\text { history of CVD in first-degree } \\
\text { relatives, energy intake without } \\
\text { alcohol, and alcohol intake }\end{array}$ \\
\hline
\end{tabular}

DII, Dietary Inflammatory Index; NHANES, National Health and Nutrition Examination Survey; HRT, hormone replacement therapy; SUVIMAX, Supplementation en Vitamines et Mineraux Antioxydants. 


\begin{tabular}{|c|c|c|c|c|c|}
\hline \multicolumn{6}{|c|}{ All-cause mortality } \\
\hline \multirow{3}{*}{$\begin{array}{l}\text { Study } \\
\text { Whitehall II }\end{array}$} & \multirow{3}{*}{$\begin{array}{l}\text { Baseline } \\
1991\end{array}$} & \multirow{3}{*}{$\begin{array}{c}\begin{array}{c}n \\
\text { (total) }\end{array} \\
7627\end{array}$} & \multirow{2}{*}{\multicolumn{2}{|c|}{$\begin{array}{c}n \\
\text { (deaths) }\end{array}$}} & \multirow{3}{*}{$\begin{array}{c}\text { Effect size }(95 \% \mathrm{Cl}) \\
1 \cdot 13(1.06,1 \cdot 20)\end{array}$} \\
\hline & & & & & \\
\hline & & & 1001 & $\rightarrow$ & \\
\hline SUVIMAX & 1994 & 7882 & 207 & & $1.09(0.99,1.20)$ \\
\hline NHANES II & 1988 & 12366 & 2795 & $\div$ & $1.04(1.02,1.06)$ \\
\hline Swedish Mammography Cohort & 1987 & 33747 & 7095 & $\frac{1}{i}$ & $1.05(1.01,1.09)$ \\
\hline lowa Women's Health Study & 1986 & 37525 & 17793 & $\rightarrow$ & $1.03(1.01,1 \cdot 05)$ \\
\hline Overall $\left(I^{2}=53.1 \%, P=0.074\right)$ & & & & $\theta$ & $1.04(1.03,1.05)$ \\
\hline
\end{tabular}

Fig. 3. Meta-analysis of studies of the association between Dietary Inflammatory Index and all-cause mortality. The boxes represent the hazards ratio and the horizontal lines represent $95 \% \mathrm{Cl} \circlearrowright$, Pooled effect obtained from combining the hazard ratio of each study. SUVIMAX, Supplementation en Vitamines et Mineraux Antioxydants; NHANES, National Health and Nutrition Examination Survey.

\begin{tabular}{|c|c|c|c|c|c|}
\hline \multicolumn{6}{|c|}{ Cancer mortality } \\
\hline var1 & var10 & var2 & var3 & & Effect size $(95 \% \mathrm{Cl})$ \\
\hline Whitehall II & 1991 & 7622 & 450 & . & $1 \cdot 12(1 \cdot 02,1 \cdot 23)$ \\
\hline SUVIMAX & 1994 & 7882 & 164 & 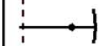 & $1 \cdot 18(1.04,1.34)$ \\
\hline NHANES II & 1988 & 12366 & 615 & í & $1.04(0.97,1.12)$ \\
\hline Swedish Mammography Cohort & 1987 & 33747 & 1996 & $i$ & $1.04(0.99,1.09)$ \\
\hline lowa Women's Health Study & 1986 & 37525 & 5044 & - & $1.04(1.01,1.07)$ \\
\hline Overall $\left(I^{2}=30.2 \%, P=0.220\right)$ & & & & A & $1.05(1.03,1.07)$ \\
\hline
\end{tabular}

Fig. 4. Meta-analysis of studies of the association between Dietary Inflammatory Index and cancer mortality. The boxes represent the hazards ratio and the horizontal lines represent $95 \% \mathrm{Cl}$. Pooled effect obtained from combining the hazards ratios of each study. SUVIMAX, Supplementation en Vitamines et Mineraux Antioxydants; NHANES, National Health and Nutrition Examination Survey.

mortality and in a lesser extent to cancer mortality while participants with higher DII- reflecting a consumption of a pro-inflammatory diet- showed higher risk of all-cause, cardiovascular and cancer mortality. Meta-analyses of the DII mortality risk reported in this study along with those from previous cohort studies, consisting of a total of 91520 participants, confirmed a higher risk of overall, cardiovascular and cancer mortality in individuals with a high DII score.

We observed concordance between the two dietary indices, DII and AHEI-2010. More than 50\% of the participants in the healthiest group of AHEI-2010 were in the most anti-inflammatory group and similar results were observed for the least healthy and most pro-inflammatory groups of AHEI-2010 and DII, respectively. This is along expected lines because components, such as vegetables and fruits, which contribute to healthier AHEI-2010 scores, also contribute to anti-inflammatory DII scores. Both adherence to a diet high in AHEI-2010 score and a diet low in DII scores constitutes a healthy diet. We did observe some discordance between the two indices. The importance of dietary features common to all: higher intakes of whole grains, vegetables, fruit and plant-based components which contribute a range of phytochemicals with potential to impact disease risk through different mechanisms working at different stages of cancer initiation and development. Differences between different indices and outcomes may reflect how other items such as fruit juice, green leafy vegetables and low-fat dairy products were considered differently by the different indices. The DII is based on the idea that many diseasedetermining mechanisms operate in a pro-inflammatory environment ${ }^{(31)}$, whereas the AHEI-2010 is based on foods and nutrients predictive of chronic disease risk ${ }^{(25)}$. The most anti-inflammatory 


\begin{tabular}{|c|c|c|c|c|c|}
\hline \multirow[b]{2}{*}{ Study } & \multicolumn{3}{|c|}{ CVD mortality } & \multirow{2}{*}{\multicolumn{2}{|c|}{ Effect size $(95 \% \mathrm{Cl})$}} \\
\hline & Baseline & $\begin{array}{c}n \\
\text { (total) }\end{array}$ & $\begin{array}{c}n \\
\text { (deaths) }\end{array}$ & & \\
\hline Whitehall II & 1991 & 7622 & 264 & $\vdots$ & $-11.17(1.03,1.33)$ \\
\hline NHANES II & 1988 & 12366 & 1233 & $\frac{1}{6}$ & $1.06(1 \cdot 02,1 \cdot 10)$ \\
\hline Swedish Mammography Cohort & 1987 & 33747 & 2399 & $\frac{1}{1}$ & $1.04(0.98,1.10)$ \\
\hline lowa Women's Health Study & 1986 & 37525 & 6528 & $\frac{1}{i}$ & $1.04(1.01,1.07)$ \\
\hline Overall $\left(I^{2}=14.6 \%, P=0.319\right)$ & & & & (1) & $1.05(1.03,1.07)$ \\
\hline
\end{tabular}

Fig. 5. Meta-analysis of studies of the association between Dietary Inflammatory Index and CVD mortality. The boxes represent the hazards ratio and the horizontal lines represent $95 \% \mathrm{Cl}$. Pooled effect obtained from combining the hazards ratios of each study. NHANES, National Health and Nutrition Examination Survey.

diets are likely to include foods that feature prominently in other 'high-quality diets'.

AHEI-2010 was found to predict all-cause, cardiovascular and cancer mortality. These results fall in line with a recent meta-analysis conducted by Onvani et al. ${ }^{(38)}$ investigating how diet quality indices as assessed by Healthy Eating, AHEI relate to all-cause and specific causes of mortality (cardiovascular mortality, cancer mortality). Conversely previous studies examining the DII-mortality association produced mixed findings. In the Swedish Mammography study, DII was positively associated with all-cause and digestive cancer mortality, but not with overall cancer mortality ${ }^{(36)}$. In the Iowa Women's Health Study, increasing DII was associated with greater risk of all-cause, CVD, digestive tract cancer, CHD and chronic obstructive pulmonary disease mortalities ${ }^{(24)}$. Among digestive tract cancers, CRC is known to be strongly related to inflammation $^{(39-42)}$ and represents the majority of digestive tract cancers $^{(20,43)}$. The DII has been shown to be associated with various digestive tract cancers including $\mathrm{CRC}^{(31,44-48)}$ and with $\mathrm{CVD}^{(49-51)}$. In a couple of other studies, the DII was shown to be associated with increased prostate cancer mortality ${ }^{(33,52)}$. Our meta-analysis including all data available confirm an association between DII, all-cause mortality, CVD mortality and overall cancer mortality. Participants with higher DII scores showed lower mean of total energy intake compared with participants with high DII score. Conversely participants in the highest tertile of AHEI-2010 were more likely to have higher total energy intake. One possibility is that the overall higher intake of food (contributing to higher overall energy intake) would encompass many anti-inflammatory dietary components amongst Whitehall II participants who consume higher amounts of food in general.

Although the mechanisms of how a healthy diet reduces mortality are not known, a plausible pathway is that a proinflammatory diet increasing systemic inflammation also increases insulin resistance ${ }^{(53,54)}$. Higher consumption of food items such as meat and butter and lower consumption of food items like vegetables and fruits has been shown to increase systemic inflammation by increasing levels of high-sensitivity CRP, E-selectin and soluble vascular cell adhesion molecule- ${ }^{(53)}$, which are then responsible for increasing insulin resistance ${ }^{(54)}$. Insulin resistance caused by increasing circulating levels of insulin, TAG, and NEFA ${ }^{(55,56)}$ is associated with an increased risk of chronic diseases, such as CVD, which can be fatal. On the other hand, the cardio-protective role of higher scores on the AHEI-2010 could be explained by other biological mediators such as arrhythmia, thrombosis, and insulin resistance ${ }^{(57)}$.

Our study has several strengths. First, it is population-based and employs a prospective design. It also, benefits from complete ascertainment of deaths through the National Health Services Central Registry until 31 August 2014, and detailed information on diet. This study also had a long follow-up for the outcomes studied. Although the DII has been used to predict mortality in a European; that is, Swedish cohort $^{(36)}$, this is the first time the DII has been used in a cohort study in Britain whose population and dietary habits are more diverse than in Sweden ${ }^{(58,59)}$. The main limitation of this study was that information on diet was self-reported, which can lead to a potential misclassification of the exposure. Classification errors in our prospective study, however, were nondifferential with respect to the occurrence of death and most likely led to an attenuation of the results. Dietary data were available only at one-time point. Participants' dietary habit might have changed during the follow-up period. However, previous studies have reported that dietary pattern classification is moderately stable over long periods of time during adulthood $^{(60-65)}$. Another important limitation of the study includes non-availability of information on the remaining eighteen food parameters for DII calculation. For Britain, with a diverse population which includes several Asian populations, availability of information on food parameters such as spices might be expected to evince different results with a more diverse food list.

In conclusion, diet indices - the AHEI-2010 and DII - that possibly reflect pro/anti-inflammatory properties of diet are 
associated with long-term all-cause, cardiovascular and cancer mortality in the UK Whitehall II study. Future steps might include investigating how these dietary indices are related to chronic inflammation and associated biomarkers.

\section{Acknowledgements}

The authors thank all of the participating civil service departments and their welfare, personnel and establishment officers; the British Occupational Health and Safety Agency; the British Council of Civil Service Unions; all participating civil servants in the Whitehall II study; and all members of the Whitehall II study team. The Whitehall II Study team comprises research scientists, statisticians, study coordinators, nurses, data managers, administrative assistants and data entry staff, who make the study possible.

Study was supported by grants from the UK Medical Research Council (MRC, K013351); the British Heart Foundation; the British Health and Safety Executive; the British Department of Health; the National Heart, Lung, and Blood Institute (R01HL036310); the National Institute on Aging, NIH (R01AG013196 and R01AG034454); and the Agency for Health Care Policy and Research (grant HS06516). Drs N. S. and J. R. H. were supported by grant no. R44DK103377 from the US National Institute of Diabetes and Digestive and Kidney Diseases. Professor M. K. was supported by the MRC and NordForsk.

M. K. designed and conducted the study; N. S. calculated the DII scores and wrote the first draft of the manuscript; T. A. performed analyses and worked on the methods and results sections of the manuscript. N. S., J. R. H., M. K. and T. A. provided suggestions and revised the manuscript. All the authors approved the final version of the manuscript.

Dr J. R. H. owns controlling interest in Connecting Health Innovations LLC (CHI), a company planning to license the right to his invention of the DII from the University of South Carolina in order to develop computer and smart phone applications for patient counselling and dietary intervention in clinical settings. Dr N. S. is an employee of CHI. The subject matter of this paper will not have any direct bearing on that work, nor has that activity exerted any influence on this project.

The authors declare that there are no conflicts of interest.

\section{Supplementary material}

For supplementary material/s referred to in this article, please visit https://doi.org/10.1017/S0007114517001908

\section{References}

1. Schwingshackl L \& Hoffmann G (2015) Diet quality as assessed by the Healthy Eating Index, the Alternate Healthy Eating Index, the Dietary Approaches to Stop Hypertension score, and health outcomes: a systematic review and meta-analysis of cohort studies. J Acad Nutr Diet 115, 780-800.e785 (Epublication ahead of print version 11 February 2015).
2. Ocke MC (2013) Evaluation of methodologies for assessing the overall diet: dietary quality scores and dietary pattern analysis. Proc Nutr Soc 72, 191-199 (Epublication ahead of print version 30 January 2013).

3. Jacobs DR Jr. \& Steffen LM (2003) Nutrients, foods, and dietary patterns as exposures in research: a framework for food synergy. Am J Clin Nutr 78, 508S-513S.

4. Ouchi N, Parker JL, Lugus JJ, et al. (2011) Adipokines in inflammation and metabolic disease. Nat Rev Immunol 11, 85-97.

5. Calabro P, Golia E \& Yeh ET (2009) CRP and the risk of atherosclerotic events. Semin Immunopathol 31, 79-94.

6. Miller MA \& Cappuccio FP (2007) Inflammation, sleep, obesity and cardiovascular disease. Curr Vasc Pharmacol 5 , 93-102.

7. Chung Y-C \& Chang Y-F (2003) Serum interleukin-6 levels reflect the disease status of colorectal cancer. J Surg Oncol 83, 222-226.

8. Terzic J, Grivennikov S, Karin E, et al. (2010) Inflammation and colon cancer. Gastroenterology 138, 2101-2114. e2105.

9. Toriola AT, Cheng TY, Neuhouser ML, et al. (2013) Biomarkers of inflammation are associated with colorectal cancer risk in women but are not suitable as early detection markers. Int J Cancer 132, 2648-2658.

10. Lin OS (2009) Acquired risk factors for colorectal cancer. Methods Mol Biol 472, 361-372.

11. Wogan GN, Hecht SS, Felton JS, et al. (2004) Environmental and chemical carcinogenesis. Semin Cancer Biol 14, 473-486.

12. de Mello VD, Schwab U, Kolehmainen M, et al. (2011) A diet high in fatty fish, bilberries and wholegrain products improves markers of endothelial function and inflammation in individuals with impaired glucose metabolism in a randomised controlled trial: the Sysdimet study. Diabetologia $\mathbf{5 4}$, $2755-2767$

13. Khoo J, Piantadosi C, Duncan R, et al. (2011) Comparing effects of a low-energy diet and a high-protein low-fat diet on sexual and endothelial function, urinary tract symptoms, and inflammation in obese diabetic men. J Sex Med 8, 2868-2875.

14. Luciano M, Mottus R, Starr JM, et al. (2012) Depressive symptoms and diet: their effects on prospective inflammation levels in the elderly. Brain Behav Immun 26, 717-720.

15. Chang AR, Lazo M, Appel LJ, et al. (2014) High dietary phosphorus intake is associated with all-cause mortality: results from NHANES III. Am J Clin Nutr 99, 320-327.

16. Cheung CL, Sahni S, Cheung BM, et al. (2015) Vitamin K intake and mortality in people with chronic kidney disease from NHANES III. Clin Nutr 34, 235-240.

17. Cohen HW, Hailpern SM \& Alderman MH (2008) Sodium intake and mortality follow-up in the Third National Health and Nutrition Examination Survey (NHANES III). J Gen Intern Med 23, 1297-1302.

18. Deng X, Song Y, Manson JE, et al. (2013) Magnesium, vitamin D status and mortality: results from US National Health and Nutrition Examination Survey (NHANES) 2001 to 2006 and NHANES III. BMC Med 11, 187.

19. Shivappa N, Steck SE, Hurley TG, et al. (2014) Designing and developing a literature-derived, population-based dietary inflammatory index. Public Health Nutr 17, 1689-1696.

20. Shivappa N, Steck SE, Hurley TG, et al. (2014) A populationbased dietary inflammatory index predicts levels of C-reactive protein in the Seasonal Variation of Blood Cholesterol Study (SEASONS). Public Health Nutr 17, 1825-1833.

21. Wirth MD, Burch J, Shivappa N, et al. (2014) Association of a dietary inflammatory index with inflammatory indices and metabolic syndrome among police officers. J Occup Environ Med 56, 986-989. 
22. Shivappa N, Hebert JR, Rietzschel ER, et al. (2015) Associations between dietary inflammatory index and inflammatory markers in the Asklepios Study. Br J Nutr 113, 665-671.

23. Tabung FK, Steck SE, Zhang J, et al. (2015) Construct validation of the dietary inflammatory index among postmenopausal women. Ann Epidemiol 25, 398-405.

24. Wood LG, Shivappa N, Berthon BS, et al. (2015) Dietary inflammatory index is related to asthma risk, lung function and systemic inflammation in asthma. Clin Exp Allergy 45, 177-183.

25. Chiuve SE, Fung TT, Rimm EB, et al. (2012) Alternative dietary indices both strongly predict risk of chronic disease. J Nutr 142, 1009-1018.

26. Marmot M \& Brunner E (2005) Cohort profile: the Whitehall II study. Int J Epidemiol 34, 251-256.

27. Akbaraly TN, Ferrie JE, Berr C, et al. (2011) Alternative Healthy Eating Index and mortality over $18 \mathrm{y}$ of follow-up: results from the Whitehall II cohort. Am J Clin Nutr 94, 247-253.

28. Brunner E, Stallone D, Juneja M, et al. (2001) Dietary assessment in Whitehall II: comparison of $7 \mathrm{~d}$ diet diary and foodfrequency questionnaire and validity against biomarkers. BrJ Nutr 86, 405-414.

29. Bingham SA, Gill C, Welch A, et al. (1997) Validation of dietary assessment methods in the UK arm of EPIC using weighed records, and 24-hour urinary nitrogen and potassium and serum vitamin $\mathrm{C}$ and carotenoids as biomarkers. Int $J$ Epidemiol 26, Suppl. 1, S137-S151.

30. Shivappa N, Bosetti C, Zucchetto A, et al. (2015) Association between dietary inflammatory index and prostate cancer among Italian men. BrJ Nutr 113, 278-283.

31. Shivappa N, Prizment AE, Blair CK, et al. (2014) Dietary inflammatory index and risk of colorectal cancer in the Iowa Women's Health Study. Cancer Epidemiol Biomarkers Prev 23, 2383-2392.

32. Sabia S, Dugravot A, Kivimaki M, et al. (2012) Effect of intensity and type of physical activity on mortality: results from the Whitehall II cohort study. Am J Public Health 102, 698-704.

33. Graffouillere L, Deschasaux M, Mariotti F, et al. (2016) Prospective association between the Dietary Inflammatory Index and mortality: modulation by antioxidant supplementation in the SU.VI.MAX randomized controlled trial. Am J Clin Nutr 103, 878-885.

34. Shivappa N, Steck SE, Hussey JR, et al. (2016) Inflammatory potential of diet and all-cause, cardiovascular, and cancer mortality in National Health and Nutrition Examination Survey III Study. Eur J Nutr 56, 683-692.

35. Shivappa N, Blair CK, Prizment AE, et al. (2016) Association between inflammatory potential of diet and mortality in the Iowa Women's Health study. Eur J Nutr 55, 1491-1502.

36. Shivappa N, Harris H, Wolk A, et al. (2016) Association between inflammatory potential of diet and mortality among women in the Swedish Mammography Cohort. Eur J Nutr 55 , 1891-1900.

37. Guolo A \& Varin C (2015) Random-effects meta-analysis: the number of studies matters. Stat Methods Med Res.

38. Onvani S, Haghighatdoost F, Surkan PJ, et al. (2016) Adherence to the Healthy Eating Index and Alternative Healthy Eating Index dietary patterns and mortality from all causes, cardiovascular disease and cancer: a meta-analysis of observational studies. J Hum Nutr Diet.

39. Erlinger TP, Platz EA, Rifai N, et al. (2004) C-reactive protein and the risk of incident colorectal cancer. JAMA 291, 585-590.

40. Gunter MJ, Stolzenberg-Solomon R, Cross AJ, et al. (2006) A prospective study of serum C-reactive protein and colorectal cancer risk in men. Cancer Res 66, 2483-2487.
41. Otani T, Iwasaki M, Sasazuki S, et al. (2006) Plasma C-reactive protein and risk of colorectal cancer in a nested case-control study: Japan Public Health Center-based prospective study. Cancer Epidemiol Biomarkers Prev 15, 690-695.

42. Nikiteas NI, Tzanakis N, Gazouli M, et al. (2005) Serum IL-6, TNFalpha and CRP levels in Greek colorectal cancer patients: prognostic implications. World J Gastroenterol 11, 1639-1643.

43. Herszenyi L \& Tulassay Z (2010) Epidemiology of gastrointestinal and liver tumors. Eur Rev Med Pharmacol Sci 14, 249-258.

44. Shivappa N, Bosetti C, Zucchetto A, et al. (2015) Dietary inflammatory index and risk of pancreatic cancer in an Italian case-control study. Br J Nutr 113, 292-298.

45. Lu Y, Shivappa N, Lin Y, et al. (2016) Diet-related inflammation and oesophageal cancer by histological type: a nationwide case-control study in Sweden. Eur J Nutr 55 , 1683-1694.

46. Shivappa N, Hebert JR \& Rashidkhani B (2015) Dietary inflammatory index and risk of esophageal squamous cell cancer in a case-control study from Iran. Nutr Cancer $\mathbf{6 7}$, 1253-1259.

47. Shivappa N, Zucchetto A, Serraino D, et al. (2015) Dietary inflammatory index and risk of esophageal squamous cell cancer in a case-control study from Italy. Cancer Causes Control 26, 1439-1447.

48. Tabung FK, Steck SE, Ma Y, et al. (2015) The association between dietary inflammatory index and risk of colorectal cancer among postmenopausal women: results from the Women's Health Initiative. Cancer Causes Control 26, 399-408.

49. O'Neil A, Shivappa N, Jacka FN, et al. (2015) Pro-inflammatory dietary intake as a risk factor for CVD in men: a 5-year longitudinal study. Br J Nutr 114, 2074-2082.

50. Ramallal R, Toledo E, Martinez-Gonzalez MA, et al. (2015) Dietary inflammatory index and incidence of cardiovascular disease in the SUN cohort. PLOS ONE 10, e0135221.

51. Garcia-Arellano A, Ramallal R, Ruiz-Canela M, et al. (2015) Dietary Inflammatory Index and Incidence of Cardiovascular Disease in the PREDIMED Study. Nutrients 7, 4124-4138.

52. Zucchetto A, Gini A, Shivappa N, et al. (2016) Dietary inflammatory index and prostate cancer survival. Int J Cancer 139, 2398-2404.

53. Esmaillzadeh A, Kimiagar M, Mehrabi Y, et al. (2007) Dietary patterns and markers of systemic inflammation among Iranian women. J Nutr 137, 992-998.

54. Festa A, D'Agostino R, Howard G, et al. (2000) Chronic subclinical inflammation as part of the insulin resistance syndrome: the Insulin Resistance Atherosclerosis Study (IRAS). Circulation 102, 42-47.

55. Bruce WR, Wolever TM \& Giacca A (2000) Mechanisms linking diet and colorectal cancer: the possible role of insulin resistance. Nutr Cancer 37, 19-26.

56. Bruce WR, Giacca A \& Medline A (2000) Possible mechanisms relating diet and risk of colon cancer. Cancer Epidemiol Biomarkers Prev 9, 1271-1279.

57. Neelakantan N, Naidoo N, Koh WP, et al. (2016) The alternative healthy eating index is associated with a lower risk of fatal and nonfatal acute myocardial infarction in a Chinese adult population. $J$ Nutr 146, 1379-1386.

58. Murakami K \& Livingstone MBE (2016) Energy density of meals and snacks in the British diet in relation to overall diet quality, BMI and waist circumference: findings from the National Diet and Nutrition Survey. Br J Nutr 116, 1479-1489.

59. Lundberg-Hallén N \& Öhrvik V (2015) Key foods in Sweden: identifying high priority foods for future food composition analysis. J Food Compos Anal 37, 51-57. 
60. Jain M, Howe GR, Harrison L, et al. (1989) A study of repeatability of dietary data over a seven-year period. $A m J$ Epidemiol 129, 422-429.

61. Jensen OM, Wahrendorf J, Rosenqvist A, et al. (1984) The reliability of questionnaire-derived historical dietary information and temporal stability of food habits in individuals. Am J Epidemiol 120, 281-290.

62. Lindsted KD \& Kuzma JW (1989) Long-term (24-year) recall reliability in cancer cases and controls using a 21-item food frequency questionnaire. Nutr Cancer 12, $135-149$.
63. Mursu J, Steffen LM, Meyer KA, et al. (2013) Diet quality indexes and mortality in postmenopausal women: the Iowa Women's Health Study. Am J Clin Nutr 98, 444-453.

64. Sijtsma FP, Meyer KA, Steffen LM, et al. (2012) Longitudinal trends in diet and effects of sex, race, and education on dietary quality score change: the Coronary Artery Risk Development in Young Adults study. Am J Clin Nutr 95, 580-586.

65. Thompson FE, Metzner HL, Lamphiear DE, et al. (1990) Characteristics of individuals and long term reproducibility of dietary reports: the Tecumseh Diet Methodology Study. J Clin Epidemiol 43, 1169-1178. 